Página inicial: 75 - Página Final: 94

Tipo de artículo: Investigación.

\title{
Transformación de subjetividades políticas juveniles, a través de un proceso formativo. i
}

\section{Transformation of Juvenile Political Subjectivities through Formative Processes.}

\begin{abstract}
Por: Carlos Darío Patiño Gaviria ${ }^{1}$ Luisa Fernanda Duque Monsalve ${ }^{2}$ Edison Eduardo Villa
\end{abstract}

$$
\text { Holguín }{ }^{3} \text {. }
$$

Recibido: junio de 2016 Revisado: noviembre de 2016 Aceptado: diciembre de 2016

\section{Resumen.}

Las transformaciones de las subjetividades políticas juveniles, en el caso de estudio realizado en la ciudad de Medellín (Colombia), fueron posibilitadas por la construcción colectiva de un espacio de "encuentro" con el otro que se caracterizó por su enfoque participativo, por la promoción del reconocimiento de la diversidad política y por el desarrollo de prácticas de reflexividad y memoria, todas, atravesadas por procesos afectivos, sin los cuales, no hubiesen sido posibles.

Palabras clave. Subjetividad política, Formación política, Participación política, jóvenes, Medellín.

\begin{abstract}
.
The transformations of juvenile political subjectivities, in the study case carried out in the city of Medellin, Colombia, were made possible thanks to the collective construction of a space of "meeting" with each other. This was characterized by a participatory approach, by the promotion of the recognition of the political diversity and the development of practices of reflexivity and memory, which are crisscrossed by affective factors, which without them, they would have not been possible.
\end{abstract}

Key words. Political Subjectivity, Political Formation, Political Participation, Youth, and Medellin.

\footnotetext{
1 Sociólogo, Magister en Educación y Desarrollo Humano, cursa estudios Doctorales en Psicología en la Universidad de San Buenaventura- Medellín. Contacto: carlos.patino@,usbmed.edu.co

2 Psicóloga, Joven Investigadora. Contacto: luisaduquem@gmail.com

${ }^{3}$ Licenciado en Lengua Castellana, Magister en Educación, cursa estudios Doctorales en el Ipecal (México). Contacto: interandinos@yahoo.es
} 


\section{Introducción.}

Los seres humanos construyen su realidad social participando de la vida en común, actuando en y sobre ella, resolviendo sus tensiones y conflictos, y creando y transformando los sentidos que orientan su vida personal y colectiva. La subjetividad tiene que ver con los sistemas de interpretación con los que se lee la realidad, que dan significado a las vivencias, orientan las acciones y generan identidades y vínculos sociales. Como construcción social, la subjetividad engloba las producciones simbólicas, estéticas, valorativas, afectivas, normativas, entre otras, que organizan las experiencias compartidas de la vida social (Torres, 2009).

Se adopta para esta expresión "construcción social", la idea de que la realidad deviene producto de tres procesos interrelacionados, la acción, la conversación y el sentimiento y, por tanto, los mismos en su movimiento van configurando y reconfigurando los sentidos de realidad de los que participan los sujetos. Por ende, la significación de las realidades, y las acciones que en ellas cobran sentido, expresan esa construcción de la misma.

En Latinoamérica se han generado planteamientos para fundamentar la categoría subjetividad política. La particularidad de dicha subjetividad se ha ubicado en la producción de sentidos y configuraciones subjetivas en torno de lo público (Díaz, 2012; Alvarado, Ospina-Alvarado y García, 2012; Alvarado, Patiño y Loaiza, 2012). Alvarado y otros (2012) sostienen que la subjetividad política se constituye en espacios de socialización política, la cual se refiere a las experiencias que forman la identidad colectiva y política del sujeto, y determinan sus relaciones con el sistema político y sus instituciones, que a su vez, se constituyen en situaciones de vivencia de prácticas y modos de relación -autoridad, comunicación, poder, género- que inciden en la creación del sujeto político (Alvarado, et al, 2012; Huerta, 2009; Lozano, 2008).

En el marco del presente trabajo, se hace un uso indistinto de los conceptos de socialización y formación política, no obstante, al campo de la "formación ciudadana" se le reconoce una acepción más específica, como estrategia para fomentar la convivencia y la justica social en el marco del reconocimiento de derechos y deberes de la ciudadanía por parte del Estado (Alvarado \& Carreño, 2007).

Las investigaciones han sugerido (Alvarado, Ospina, Botero \& Muñoz, 2008), que la formación o socialización política no debe apuntar tanto a ofrecer contenidos y transmitir principios del sistema político, como a crear condiciones para que los sujetos se reconozcan como protagonistas de su historia a partir del conocimiento de sí mismos y de sus realidades, y a través de su participación en propuestas colectivas de organización social, más que desde las instancias procuradas por el Estado.

Los hallazgos de las investigaciones, señalan que la formación política se produce en las experiencias concretas y contextuadas de participación (Henao, Ocampo, Robledo \& Lozano, 2008), que se tienen que comprender en su historicidad y en el marco de juegos de poder susceptibles de ser transformados, lo que requiere de acciones así mismo contextualizadas para desestructurarlos (Botero, Ospina, Gómez, \& Gutiérrez Ospina, 2008).

De otra parte, la pedagogía deliberativa se ha considerado como una opción relevante para la formación política, ya que la deliberación en situaciones de tensión y conflicto de valores, producen desencuentros que obligan a profundizar en la búsqueda de soluciones y en la

\begin{tabular}{l|l|l|l|l|l|l} 
AGO.USB & Medellín - Colombia & Vol. 17 No. 1 & PP 1 - 323 & enero - junio & 2017 & ISSN: 16578031
\end{tabular} 
compresión de problemáticas (Magendzo, 2007). Estos espacios requieren de condiciones de confianza, equidad y simetría como base de la participación (Roldán, 2006). También se reconoce que estos procesos deben ser orientados a la luz de enfoques críticos y políticos (Alvarado et al. 2008; Botero et al. 2008), por lo cual las llamadas pedagogías críticas también se vislumbran como alternativas con una apuesta clara por "procesos de emancipación, democratización y liberación que permitirían a hombres y mujeres construir realidades radicalmente diferentes" (Agudelo \& Gaviria, 2014, p.274).

Se hace evidente, además, que las prácticas políticas juveniles en Medellín, se presentan en un contexto en que al joven sigue viéndosele como víctima y victimario, en una ciudad que sigue produciendo sentimientos de marginación en los jóvenes debido al protagonismo de la violencia y de la exclusión social y económica (Restrepo, 2010).

En este estudio se reconoce que la subjetividad política crea sentidos y orienta acciones instituyentes de nuevas formas de vida social alternas a las prácticas, relaciones, roles y creencias dominantes en el ordenamiento de lo público (Díaz, 2012; Bonvillani, 2012). De esta manera la subjetividad misma se transforma de acuerdo con las posibilidades subjetivas y materiales que ofrece un contexto histórico y social con sus tensiones. Dichas tensiones tienen lugar entre tendencias que apuntan a la institución de nuevas formas de circulación del poder, como entre tendencias que consciente o inconscientemente, tienden a la perpetuación de las condiciones dadas (Duque, Patiño, Muñoz, Villa \& Cardona, 2016).

El presente estudio acepta la premisa de que, si la formación política trasciende sus orígenes conservaduristas y afirmativos, que hacen uso del disciplinamiento y la instrumentalización de lo político (Runge, 2005; Vierhaus, 2002), podría constituirse en una manifestación de los procesos de emancipación humana en el marco de una formación no afirmativa o crítica (Benner, 1998; Lüth, 2001). Reconoce también que los procesos formativos requieren de las incitaciones sociales, de procesos que afectan al sujeto, al que se le reconoce una función activa, de modo que la formación siempre es auto-eco-formación, puesto que no es posible formar a un sujeto si éste no tiene la voluntad de darse esa forma a sí mismo y a la vez, sería transformación, que es lo que se quiere establecer y validar con el estudio.

Ahora, el supuesto de la auto-eco-formación reconoce que las incitaciones no determinan totalmente a los sujetos, sino que estos se forman en relación dialógica con los otros, en contextos históricos concretos. Así mismo, la formación crítica de las subjetividades es dinámica y procesual, puesto que implica un permanente dejar de ser para devenir otro, es decir, como agente que experimenta subjetivaciones políticas (Tassin, 2012).

En todo caso, la formación de sujetos políticos se sigue viendo como una necesidad ante la precariedad y banalización de la política expresada en la frustración, desconfianza e impotencia política que sienten los jóvenes, y su repliegue en la vida privada (Alvarado, et al, 2008).

Mirando hacia el contexto de la ciudad, si bien existe diversidad de colectivos juveniles que trabajan con un sentido político en torno a la ecología, el feminismo, la objeción de conciencia, la memoria, etc., sólo el $2.9 \%$ de los jóvenes se vinculan a escenarios de participación institucionales (Alcaldía de Medellín, 2012, 2015). Por ello ha sido un propósito de la política pública de juventud promover la participación en espacios institucionales, como a través de otras formas de participación juvenil (2015, p.294).

\begin{tabular}{l|l|l|l|l|l|l} 
AGO.USB & Medellín - Colombia & Vol. 17 No. 1 & PP 1 - 323 & enero - junio & 2017 & ISSN: 16578031
\end{tabular} 
En síntesis, el tema de la formación de las subjetividades política de los jóvenes ha adquirido relevancia (tanto para los investigadores como para instancias estatales), como respuesta ante la baja participación de estos en escenarios convencionales, pero también como reconocimiento a las potencialidades de los sujetos juveniles para generar transformaciones políticas y relaciones sociales democráticas, deliberativas, críticas, sensibles, solidarias y creativas, en medio de la diversidad de sus formas de participación. El presente artículo, resultado de investigación, se une a dichos esfuerzos para contribuir a entender cómo devienen transformaciones de las subjetividades políticas juveniles, en un espacio pedagógico al que concurren para poner en común sus experiencias cotidianas de enfrentar diferentes modos de relaciones de poder.

Por ello, el objetivo principal que se ha propuesto esta investigación es el de comprender el proceso de transformación de subjetividades políticas de jóvenes de Medellín, en el marco de un espacio de formación orientado a la construcción colectiva de sujetos políticos.

\section{Metodología.}

El estudio tuvo un diseño cualitativo y se abordó a la luz de un enfoque interactivo y comprensivo, que reconoce la capacidad de los sujetos personales y colectivos para coparticipar de procesos reflexivos, dialógicos y constructivos de su realidad significativa y práxica. A esta intención, se subsumieron estrategias participativas y reflexivas que orientaron las actividades educativas. El modelo operó sobre una lógica de acción-reflexión, pues los participantes llevaron a cabo tareas de carácter colaborativo para producir interpretaciones y sentidos colectivos como saberes propios.

El espacio formativo es de un enfoque participativo y por ello se incluye estrategias como: talleres, debates, salidas de campo, exposiciones de invitados - quienes compartieron sobre sus experiencias organizativas-, técnicas artísticas (escenográficas y plásticas), etc. Es importante aclarar que los facilitadores no agenciaron discursos académicos sobre los temas abordados.

El grupo resultó de una convocatoria a la que se acogieron inicialmente 15 jóvenes, de los cuales 10 terminaron el proceso, Tres dejaron de asistir en los comienzos y dos de ellos, poco antes de terminar. Se trabajó con un criterio de pluralidad y no de homogeneidad, por lo cual los participantes podían tener experiencia en procesos organizativos o carecer de ella. Los participantes representaban procesos sociales y políticos diferentes: estudiantes de secundaria con experiencia de movilización estudiantil; miembros de un colectivo de resistencia a la guerra; estudiantes universitarios; líderes comunitarios y líderes de organizaciones religiosas de base. Al tratarse de un estudio cualitativo no se buscó que la muestra tuviera representatividad estadística, pero sí se pretendió que tuviera representatividad cualitativa (Galeano, 2004), esto es, que los colaboradores representaran en sus discursos diferentes experiencias de participación juvenil en la ciudad, de ahí el criterio de pluralidad del que se ha hablado. Por lo demás, se buscó conformar un grupo pequeño de participantes con el fin de tener un mejor acceso a los procesos de comunicación e interacción de los participantes y validar no tanto experiencias individuales como transformaciones subjetivas producidas a partir de lo que los jóvenes produjeron entre sí.

Para producir información, se privilegió el taller colaborativo-reflexivo que fue motivo de un registro observacional por los investigadores, el cual contenía descripciones sobre lo acontecido, 
acompañadas de evidencias icónicas, productos elaborados por los participantes, grabaciones (que posteriormente fueron transcritas) y otras evidencias.

Se realizaron entrevistas semi-estructuradas por subgrupos, como técnica complementaria de producción de información. La guía se construyó con base en un análisis preliminar de las memorias y transcripciones de los encuentros formativos. Estas tuvieron como objetivo incitar reflexiones en los participantes sobre su tránsito por el evento para entender qué se vivió y eso cómo fue formando parte de la reconfiguración de sus subjetividades.

Los registros de observación participante, las narrativas autobiografías escritas por los colaboradores y las transcripciones de los debates y las entrevistas fueron organizados en una matriz para facilitar su lectura, codificación e interpretación. Los datos fueron sometidos a inducción analítica, de modo que se produjeron categorías emergentes con las cuales se pudo comprender las transformaciones de subjetividad política. Los hallazgos fueron cotejados con un subconjunto de los participantes para que contribuyeran con su validación. Los datos se pusieron en relación para generar las interpretaciones, teniendo en cuenta los contextos de producción de información y los propósitos formativos.

Vale aclarar que, en el desarrollo del presente texto, los testimonios provenientes de entrevistas se citan con la letra E, seguida del número de la entrevista de acuerdo con el orden cronológico de su realización; a continuación, se consigna el mes y año.

\section{Resultados.}

El espacio de formación política, se entiende como un momento en el devenir de las subjetividades políticas de los participantes, las cuales experimentan otros encuentros. No se trata de un momento definitivo o excepcional, pero sí de una situación que, con todas sus limitaciones temporales, espaciales, metodológicas y temáticas, tuvo incidencia en la vida política de los participantes. A continuación, se expone una descripción sobre las condiciones que en el proceso posibilitaron la reconfiguración de subjetividades políticas.

\section{Encuentro con lo Diferente.}

Uno de los aspectos relevantes, de esta investigación, es que el proceso formativo se constituyó, antes que nada, en un encuentro que adquirió el carácter de condición agenciante de reconfiguraciones de la subjetividad política. ¿Qué sería un encuentro en un espacio formativo? ¿Qué deviene de él, en tanto que condición agenciante? El encuentro configura un espacio social creado, en el aquí y el ahora, aunque portando los sedimentos históricos que allí se vierten, a manera de tradición, de lo instituido y de lo recordado, inclusive, de lo que los cuerpos portan consigo. Ese espacio, en cualquier caso, concreto, es de producción de la vida. Es espacio vivenciado (Runge \& Muñoz, 2005).

En el proceso formativo, el encuentro es un acontecimiento que rompe rutinas, modifica el espacio perceptual de los participantes, concita la diversidad expresiva, aglutina experiencias diversas. En un principio, los jóvenes llegan con su ímpetu, pero también con sus reservas, a diseñar el ideal pedagógico que integraría tanto a los sujetos encargados de coordinar el proceso formativo, como a los que se suman a la nueva experiencia. 
Este encuentro produce su realidad: jóvenes que tienen entre sí marcadas diferencias, en relación a la edad, al barrio de procedencia, a las condiciones socioeconómicas, al nivel académico, a las experiencias de formación política, a las tendencias ideológicas, etc., pasaron a constituir una nueva unidad, una situación en la que las interacciones se hicieron productivas. Valga señalar que las experiencias de participación política por las que han pasado incluían el arte/performance, las acciones comunitarias con compromiso político, las acciones politicas convencionales (peticiones y solicitudes), las acciones politicas en escenarios cotidianos y movilizaciones estudiantiles. Por todo lo anterior, el proceso formativo, como situación, hizo que se fueran desvaneciendo los archipiélagos, para configurarse como continente, que produjo su contenido.

El espacio puso en relación lo diferente que se hizo propio; un encuentro que en principio generó "choque", y que a veces incomodó, pero que también inspiró, interesó y movió la sensibilidad de los jóvenes. En esto coincide uno de ellos:

y los puntos de vista eran totalmente distintos. Había personas con las que uno podía discutir desde ángulos distintos a los que se enfrenta durante toda su vida. Fue algo muy agradable desde mi punto de vista. $(\mathrm{E} 4,08,2015)$

El encuentro produce acercamientos, reconocimientos y a la vez, distancias en torno a argumentos, ideales, sentimientos y prácticas que sustentan las diferentes posturas políticas de los participantes, es posibilidad de descubrimientos, de novedades; la palabra del otro acerca a universos ignotos y significativos:

(...) tantas cosas que uno vive en la sociedad, vive en Medellín, y deja esos temas a un lado, porque a uno le parecen como normales o extraños, y en cambio aquí con estos muchachos aprendí que hay gente que lucha por cosas que yo nunca supe... cómo hablaban de cosas que uno nunca en la vida tocaba esos temas $(\mathrm{E} 9,08,2015)$

(Presenciar el performance) fue como abrir un mundo que yo no conocía... me hizo tener como una opinión, como un choque, porque realmente yo veía un militar y yo decía como, eh!... (E7, 08, 2015)

El performance al que se refiere el testimonio, es una puesta en escena de una obra de carácter antimilitarista.

El encuentro sirve de escenario de re-creación de sus marcos de interpretación y de construcción de nuevos sentidos políticos que sirven para hacer nuevas lecturas -críticas- de la realidad. El sujeto problematiza lo que antes le parecía normal o extraño: para él se hace visible lo que antes le era invisible. Así entonces, en el encuentro formativo el sujeto juvenil cualifica su mirada, se sensibiliza y cuestiona; queriendo saber más.

Lo más impactante de esto fue la sacada que me pegó de la burbuja en la que toda mi vida he estado viviendo, porque mis puntos de vista políticos se han visto influenciados por el ambiente en el que crecí, [donde] no hubo nunca presencia armada (...) y ver las experiencias de otras personas en este sentido, cambia muchos puntos de vista, desde mis concepciones acerca de figuras políticas hasta, por ejemplo, mi percepción de lo que es el sistema militar colombiano (E4, 08, 2015).

El encuentro crea provocaciones que se desarrollan en otros contextos, que cada quien asume según sus posibilidades y así subjetiva una experiencia que luego es compartida. A veces 
enriquece los marcos de compresión políticos y también puede contribuir a transformar posturas políticas en mayor o menor medida;

Tratando como de entender cada punto de vista (...) ir escogiendo como las cosas con las que yo me sentía de acuerdo y escuchando esas cosas con las que a veces uno no se siente de acuerdo, pero escuchando, porque es lo que necesitamos en esta sociedad, escuchar, pensar, razonar y no irnos solo por la tradición (...). (E6, 08, 2015)

En este proceso también se genera el deseo de hacer cambios en la propia vida política, en los marcos de referencia, por ejemplo, dándole valor a la vida cotidiana como espacio de vivencia de lo político.

(...) lo viví (el debate) de una manera muy vivaz (...) me tocó profundamente (...) esas vivencias que escuché en el debate, ahora lo que importa en verdad es la gente para mí y no tanto una estructura teórica, salí con otra posición, porque una cosa es lo que uno está acostumbrado a escuchar, a leer de política y otras cosas es cuando uno escucha y se empantana de las vivencias del común. (E5, 08, 2015)

La construcción y compartición de los relatos autobiográficos, sobre los procesos políticos de los que había hecho parte cada uno, también se situó como condición de transformación subjetiva. En especial el hecho de producir un escrito propio y ponerlo en común agencia posibilidades de articulación de historias, de subjetivaciones próximas, de vidas cruzadas por procesos sociales similares: "el tratar de hilar la historia a partir de lo que el otro contó, nos invita a encontrarnos con el otro; en la diferencia, así sea en lo más pequeño, también nos podemos encontrar" (E2, 08, 2015).

\section{Posicionamientos Políticos y Emergencia de Tensiones.}

Las discusiones son acciones fundamentales para la vivencia de lo político y la construcción conjunta de significados. En estos intercambios comunicativos los sujetos se motivan por conocer las posturas políticas de los otros, encontrar convergencias y divergencias o modificar sentidos subjetivos:

Cada uno ponía un aporte diferente frente a la construcción de la categoría de lo político, cada uno sabía lo que para uno significaba, entonces lo que quería saber era para el otro qué significa, a tal punto se notó eso, que no llegamos a un consenso de esa diversidad. (E1, 08, 2015)

En principio, los sujetos juveniles no son conscientes de las connotaciones políticas de sus posturas, o aún del acto político que implica su defensa. Pero en la discusión, se ponen en juego los marcos de comprensión que remiten en algunos casos al trabajo colectivo de las organizaciones juveniles, e incluyen rastros de discursos académicos o saberes de la vida cotidiana; los ideales políticos; las justificaciones de sus modos de acción y los cuestionamientos -morales y políticos- a las posturas de otros participantes. Además, se proponen alternativas de acción política, se exhorta a los interlocutores a cambiar ciertas concepciones o prácticas, y se contra-argumenta con estilo persuasivo.

Las diferencias que emergen en las discusiones sirven de basamento para las confrontaciones, y de manera consecuente devienen tensiones entre las posturas políticas esgrimidas por los participantes, promoviendo efectos de problematización y ensanchamiento de los horizontes de 
sentido. Las confrontaciones pueden llegar a ser acaloradas -tono de voz fuerte, semblante beligerante, interrupciones de la palabra, talante imponente, falta de escucha, etc.- Un participante describe así una de las tensas situaciones vividas:

Me puse a pelear con él (conferencista invitado) y él me miró muy feo porque yo me puse a defender el capitalismo por ser medio polémico, y él se enojó (...) pero fue interesante ver qué puntos él pone y cómo contradice lo que tú dices. (E4, 08, 2015)

Las confrontaciones generan un ambiente emocional cruzado por diferentes sensaciones que pasan por la incomodidad, pero también por el entusiasmo y el interés. En el contexto de esta ambigüedad afectiva, en ocasiones el malestar toma protagonismo y algunos pierden el interés en los debates. En medio de una discusión se produjo una pausa y se generó el siguiente diálogo entre participantes que enfrentaban posturas:

P1: (Con tono de desánimo) Es muy bacano el debate ¿pero a qué vamos a llegar con esto? Porque acá yo puedo exponer mis razones de por qué yo soy antimilitarista y usted pro-militarista ¿Pero a qué vamos a llegar con esto? (risa irónica).

P2: (pasados varios segundos el otro joven le contesta en tono reconciliador): pues conocer qué piensa el otro sobre esto... (El debate prosiguió). (P2)

Las diferencias políticas se reflejan en distancias interpersonales, rivalidad y deseos de imponerse entre los participantes, lo que reafirma la idea de que lo político no es una esfera independiente de los afectos y relaciones personales. El deseo de alejarse de los otros, producto de la incomodidad que suscita la diferencia, puede convertirse en la génesis de actitudes excluyentes. Tal deseo, según se viene sosteniendo, podría tener su base en la conflictividad emergente en el proceso de creación de identidades, que se forman a partir de la distinción entre el "nosotros" y el "ellos" (Tajfel, 1984). Las reacciones de malestar y distanciamiento, más que racionalmente decididas son relativas al "gusto", a la sensibilidad que surge frente al otro en el encuentro. En relación al impacto emocional de las confrontaciones, los sujetos niegan, sin ser conscientes, los supuestos ético-políticos que dicen defender: se excluye la diferencia.

No obstante, los sentimientos de desconfianza, los prejuicios y la reticencia de algunos frente al debate político, se van transformando, en tanto algunas condiciones van dando paso a que se produzcan otras realidades; sobre esto se enfocará el siguiente apartado.

Como se ha enunciado, las tensiones y las pugnas son definitorias de lo político al ser consecuencia necesaria del encuentro de posturas diferentes que se juegan su reconocimiento, la posibilidad de incidir en la orientación de la vida colectiva, o que, como este caso, se disputan la legitimidad de sus interpretaciones y posicionamientos con respecto a la realidad social. Para que la conflictividad inherente a las relaciones políticas pueda devenir en un ejercicio democrático, se requiere que aquellas puedan ser dirimidas por vías legítimas (Mouffe, 2007) y que se logren superar las exclusiones, imposiciones, repliegues y desmotivaciones que suelen permear el mudo de lo político.

\section{Tramite de las Tensiones y Reconocimiento de la Diferencia como Práctica Política.}

Desde el principio los jóvenes van creando los acuerdos para regular sus relaciones en el espacio. Una acción que se convierte en un ejercicio político mediante el establecimiento de 
acuerdos como: respeto y no censura ante las diferencias en concepciones políticas-ideológicas, escucha activa, participación, apertura frente a lo que el otro dice, trato fraterno para posibilitar el trabajo colaborativo. De ahí que en el espacio no sólo se construyeron saberes sobre lo político, sino que se vivió lo político.

Estos acuerdos se van llenando de sentido en el camino recorrido: en las situaciones de acalorada discusión los participantes encuentran la forma de autorregularse para impedir conductas irrespetuosas. En una situación en la que, en medio del apasionamiento se interrumpían la palabra, una de las jóvenes llamó la atención:

Considero que debemos escucharnos, partamos de los principios que ya tenemos acá (señala acuerdos fijados en la pared) ... y no tener que entrar a rebatirle a otro, de una, su palabra, porque es que la palabra se respeta. (P1)

El llamado surte efecto. Ahora bien, cuando no todos los acuerdos se pueden realizar de la manera convenida, sí se respetan aquellos relativos a la convivencia. A pesar de las tensiones, los participantes se sienten acogidos, respetados y escuchados.

El trabajo conjunto posibilita construir en común y hacer emerger una atmósfera de cercanía afectiva. La interacción con el otro, va ayudando a crear un ambiente de confianza, que así fuera incipiente, contribuyó a limar las asperezas iniciales. Los jóvenes van identificando la necesidad de trabajar con quienes tienen mayores diferencias y van rompiendo las desconfianzas con el transcurrir de los encuentros:

Me sentía como interesado en trabajar con él, porque de entrada sí identifiqué esa diferencia (...) yo quería estar más cerca y no porque me sintiera cómodo (...) sino para saber por qué lo pensaba y por qué me tenía que encasillar. (E1, 08, 2015)

Sí hubo cambios (...) porque uno a veces cuando trata a una persona lo hace cómo como con miedo; hay dinámicas que hacen que las personas se conozcan mejor o que empiecen a coger como confianza (...) uno sí siente transformaciones y uno dice: si hay diferencias en muchas cosas.... (E2, 08, 2015)

Los acercamientos personales también tienen el potencial de posibilitar el reconocimiento político del otro. Quienes se sienten desmotivados para participar en las discusiones van experimentando cambios que les llevan a percibirlas como necesarias para que otros también puedan aclarar sus posturas y permitir el trabajo de creación conjunta.

Los modos de interacción se van modificando en tanto se va materializando el deseo de ser consecuentes con la premisa de que lo político, y el encuentro, se tienen que construir en medio de las diferencias. Reflexivamente se volvió sobre las tensiones para resignificarlas:

Referente a mi formación política pues, creo que ahora veo de una manera distinta a aquellos miembros de la sociedad que pertenecen a otros partidos que son, tienen ideas diferentes porque, ya que las he visto desde un contexto distinto, tienen mucha razón en lo que dicen, aunque no estoy completamente de acuerdo con ellos. (E4, 08, 2015).

La resignificación en este contexto se entiende como modificación de versiones del pasado y posibilidad de generar interpretaciones alternativas frente a una situación (Molina, 2013). 
Este testimonio, da cuenta de un acto de subjetivación en el que vuelve sobre la experiencia producida interactivamente para sacarle provecho formativo y político. Se trata de un acto transformador puesto que opera sobre la base de las re-significaciones de las tensiones vividas. Pensar sobre lo vivido en una espacio-tiempo diferente, procura una suerte de "enfriamiento" emocional que potencia la reflexividad y que en este caso sirve para valorar positivamente el encuentro, a veces incómodo, con lo diferente.

El hecho de que algunos de los jóvenes que no concluyeron el proceso, lo hicieron precisamente en razón de las tensiones suscitadas, lleva a pensar que, a pesar de lo acordado, resulta difícil generar escenarios con las condiciones propicias para que la construcción conjunta se produzca a través de la puesta en escena de las diferencias.

Por tanto, si bien persisten diferencias, las tensiones se van tramitando a lo largo del camino, de modo que el mismo proceso formativo se constituye en espacio de reconocimiento del otro, en tanto práctica política. Se entiende el reconocimiento como la posibilidad de que los otros diversos, sean a la misma vez, reconocidos como iguales en dignidad y legitimidad en tanto representantes de opciones políticas diferentes. Lo significativo, es que entre los participantes se produce esta comprensión:

(...) es que, de alguna manera, ya estamos empezando a convivir, estábamos conviviendo desde la diferencia, porque a lo último, por ejemplo, una de las últimas conversaciones (...) sí fue un tema álgido en términos de la diferencia, pero no salimos con esa espinita con la que salíamos siempre. (E1, 08, 2015)

Por lo demás, estas prácticas de reconocimiento no sólo tienen lugar en este espacio formativo, sino que son necesarias donde quiera que se vaya a realizar un trabajo colectivo con sentido político. La superación de brechas ideológicas a través de reflexiones compartidas lleva a identificar lo razonable en el punto de vista del otro, así no se esté de acuerdo él:

(...) y en este momento hago conciencia de que podemos construir desde la diferencia, (...) las discusiones pueden ser muy fuertes, pero uno se calma, debe encontrar los puntos débiles, porque no debemos estar en acordes para trabajar conjuntamente. (E1, 08, 2015)

También, quienes viven con incomodidad el desacuerdo, alcanzan la consciencia de que tienen que entender a los otros si quieren sustentar su propia posición.

Esto solo es posible en un espacio con ciertas condiciones, que fomenten el respeto mutuo, incentiven el diálogo y en el que los participantes tengan una actitud -política y ética- de apertura. Esta actitud es posible cuando el sujeto sabe que no tiene todo resuelto y por lo mismo se esfuerza en darle cabida a lo otro desde el marco de referencia del que proviene.

Todo lo anterior, conduce a la idea de que el espacio de encuentro se constituye en una fuente de experiencia política, si se entiende que el evento produce un encuentro tenso entre diversidad de subjetividades políticas juveniles, y que esas tensiones se tramitan en ese espacio a través de mecanismos generadores de reconocimiento recíproco a partir de los cuales se distingue lo común y lo diferente, y además se construye la significación de que las opciones políticas son múltiples. 
Además, sale a la luz la importancia de la dimensión afectiva para llegar a la práctica del reconocimiento puesto que, en la situación de encuentro la creación de cercanía y confianza entre los participantes es imprescindible para tal fin, así como la capacidad de recobrar la calma y reflexionar sobre lo vivido. Pero también se necesita de la vehemencia, concomitante a la vivencia de las tensiones en la situación de aprendizaje.

\section{Acciones de Reflexividad y Memoria.}

La reflexividad se entiende como el proceso mediante el cual la propia actividad se vuelve objeto explícito para el sujeto, tiene que ver con los actos de volver sobre sí y "pensar-se" que ayudan a conseguir un sentido de coherencia e identidad política (Díaz, 2012). No es un acto solipsista, puesto que el sujeto siempre se piensa en relación con otros y con su realidad social, reflexiona sobre las diversas identidades -sociales y políticas- que lo han constituido; tomar conciencia de sí implica situarse histórica y socialmente.

El encuentro propicia procesos de reflexividad en tanto promueve un encuentro de los colaboradores, en tanto sujetos políticos, a través de la interacción con otros -que les pide escribir una autobiografía, les interpela en un debate, les cuenta sus experiencias, etc.-. Por otra parte, evocar lo vivido y reflexionar sobre ello, conduce a los participantes a construir nuevas valoraciones y significaciones que empiezan a hacer parte de sus marcos de interpretación. Por lo tanto, se reconoce la transversalidad de los procesos de reflexividad y memoria en el camino recorrido, pero en este apartado se hará énfasis en su papel con respecto a transformaciones de la subjetividad política.

Gracias al proceso reflexivo se viven descubrimientos, al modo de un "darse cuenta" de quién se es como sujeto político. La formación política implica de manera inseparable actos reflexivos y de memoria, referidos a la evocación e interpretación de su propio devenir político, desde donde retoman el aliento para participar políticamente. Asimismo, van reconociendo los posicionamientos en los que han ido construyendo como sujetos políticos, acercándose y diferenciándose de otros. Los jóvenes se dan cuenta de las tradiciones que los permean, y ubican sus experiencias biográficas en un marco social, otorgándoles un sentido político y posibilitando lecturas críticas.

La reflexividad apunta a un "recoger la experiencia" mediante interconexiones que se van haciendo explícitas, y por lo mismo, los participantes valoran el lugar de los ejercicios de memoria en la construcción de sí mismo y su importancia para encontrarse con otros a través de los recuerdos evocados, que resultan ser compartidos. Si bien la autobiografía política, la escriba cada participante, hay un momento en el que cada uno escoge leer algún fragmento para compartirlo con sus compañeros, lo que genera condiciones para que, entre algunos de ellos, se vean reflejados en historias de otros, o se vean extrañados allí. En todo caso se crean hilos de proximidad, al punto que se descubre una historia relativamente compartida.

El acto de memoria compartida, como escenario de encuentro de subjetividades, se hace por sí, y por la participación dialogal, plataforma de re-significación de experiencias y dolores, sin desestimar que el acto de hacerlo con el otro, produce alivio emocional. En el proceso de resignificación los dolores que se sienten privados, se logran comprender en el marco de procesos sociales y políticos. 
Lo de mi hermano sí, pues, yo no lo había visto así, no lo había pensado así. Es algo que tiene que ver con esas políticas de muerte, de exterminio a los jóvenes (...) Ese día fue que yo me puse a verlo, que tiene que ver pues con eso (E3, 08, 2015).

Por otra parte, no sólo se pone la mirada sobre el pasado, la reflexión sobre la propia subjetividad política permite soñar con esperanza sobre las posibilidades aún no realizadas, de incidir en el orden social.

En relación con este lugar que el sujeto ocupa en la vida política, se identificó la recurrencia y la importancia de los procesos de autocrítica mediados por la reflexividad sobre sus propios actos o los trayectos recorridos en las organizaciones a las que pertenece. La autocrítica adquiere relevancia al movilizar credulidades, puesto hace nacer cuestionamientos e interroga motivaciones, posicionamientos y acciones políticas, para desde allí generar los cambios que se consideren pertinentes:

"Yo misma he puesto los obstáculos para no participar" (Participante, transcripción de la sesión, 06, 2015), es lo que llega a reconocer una participante en medio del diálogo con un compañero. Afirma que la corrupción con la que se ha encontrado en diferentes ámbitos de participación, no puede seguir siendo una excusa para alejarse de la actividad política, sobre todo cuando siente que ama la participación comunitaria. Otros jóvenes, por su parte, afirman en relación al encuentro formativo:

Para mí fue un ejercicio de reflexión que tomó un par de semanas desde la construcción de la biografía hasta la entrevista, y bueno, fue un tanto impactante, pero fue un catalizador, por decirlo así... me di cuenta de que estaba desperdiciando mis capacidades. (P3)

Por otra parte, vale la pena resaltar que la reflexividad también posibilita la transformación del sentido de lo político para los participantes, sin que este cambio fuera directamente promovido por los facilitadores. La transformación de la que aquí se habla tiene que ver con el reconocimiento de las realidades sociales y cotidianas (p.ej. reivindicaciones comunitarias) como espacio de vivencia de lo político. Esta subjetivación genera interés sobre problemáticas y modos de acción política propias del contexto de los jóvenes y por otra parte, conduce a reconocer que lo político no es ajeno a ellos (no es un asunto de expertos), ni está limitado a teorías o formas de participación convencional Estado-céntricas (Alvarado, et al. 2008), no es sinónimo de politiquería, corrupción y partidos, por lo cual no tiene que dar "pereza" o "asco". Reconocer lo político como un asunto de todos, que cruza diversos momentos de la vida social y que se relaciona con la toma de decisiones para resolver problemáticas sociales y con la búsqueda del bien común, lleva a la consideración de que todas las relaciones y acciones pueden llegar tener una connotación política en determinado momento. A través de esta re-significación el sujeto se descubre a sí mismo como sujeto político (aunque en algunos casos sea poco activo y crea que le falta saber más) y se libera de la apatía hacia a la política cuando se la reconoce como parte de sí mismo y sus relaciones cotidianas.

\section{Discusión.}

La formación de subjetividades políticas juveniles: un producto del Encuentro. 
La vida cotidiana deviene contexto de construcción, lo que le da a la acción humana y a la experiencia, un carácter situado y con sentido. Los espacios sociales y públicos constituyen escenarios humanos de reconocimiento y reciprocidad, donde, gracias al encuentro, las subjetividades entran en diálogo. El encuentro llena los espacios. De allí el valor que para el proceso formativo implican los espacios pedagógicos (Runge \& Muñoz, 2005). Estos logran el cometido de favorecer la reflexión crítica en cuanto a su potencial de transformación, con respecto a aquellas suposiciones que han contribuido a mantener relaciones de dominación.

Las interacciones por su parte, son la realización regular y rutinaria de los encuentros, son situaciones sociales completas, no actos de transmisión de información. La situación se constituye en intersubjetividad, una materia que le es común a los participantes y define las condiciones de interacción y producción de sentidos (Fernández, 2009).

El encuentro es una experiencia compartida, un acontecimiento psicosocial que configura un hecho colectivo, del que participan, crean y recrean los actores. Esta experiencia va dejando contribuciones formativas relacionadas con la convergencia de la diversidad; el descubrimiento de otros universos de acción y comprensión de realidades sociales y políticas; el enriquecimiento de marcos de interpretación para problematizar y criticar, y sobre el papel de las incitaciones para recrear experiencias en otros escenarios; todo a través de metodologías participativas que fueron estimulando el trabajo colaborativo y la discusión, así como los procesos de cualificación de la subjetividad política.

Pues bien, todo encuentro es con otro, y produce efectos a partir de la trama de acciones de los participantes, lo que lo hace siempre nuevo. Por ello, así pensado, ha movilizado subjetividades, pues estas van reconfigurando sus certezas y adoptando otros modos de comprensión sobre el mundo pluriverso en el que se desenvuelven. El encuentro involucra dos dimensiones: la de la comunicación (que incluye la interacción), y la de la acción. La segunda se complementa con la primera. Toda acción es simbólica para el otro. El encuentro pone a los participantes en un curso de acción conjunta en el que la palabra conecta y crea, así como también, distingue. Además, en él se producen tres cosas: saberes, afectos y construcción de espacio político. Dirimir diferencias; conciliar desencuentros; acercar polos ideológicos; generar confianza pública entre diferentes, construir referentes comunes; revisar creencias mantenidas por años, nutrir el lenguaje, aceptar que hay trayectorias diversas del sujeto político, revisar la propia historia y encadenarla a la historia de los otros, todo ello es creación de espacio político de trans-formación de subjetividades políticas juveniles. En ello se coincide con Arendt (1997), en tanto la acción como política va acompañada de la palabra (lexis), pues se percibe el mundo desde la posición que ocupamos en él, por lo que sólo podemos experimentarlo como mundo común en el habla. "Sólo hablando es posible comprender, desde todas las posiciones, cómo es realmente el mundo. El mundo es pues lo que está entre nosotros, lo que nos separa y nos une" (Arendt, 1997, p.19).

En el encuentro las diferentes trayectorias e historias se van integrando, no sin tensiones, a partir de acuerdos que incluyen la escucha activa, reglas de actuación y compromisos. Por lo tanto, fue configurando el terreno de la política: terreno donde se tramitaron las diferencias y las tensiones. ¿Pero eso qué va a significar? Que, al ser asumido con compromiso, se fueron generando disposiciones, aperturas, confianza y tramitación de las tensiones. Es decir: comunicación. Esto, en términos de devenir, de movilidad, va conduciendo a que se constituyese en espacio para reconsiderarse o para reconocerse, sin decir que las diferencias se 
salvasen o que las tensiones quedasen resueltas. Los modos de acción compartidos, van resolviendo lo que en un principio distancia y opone. Ese movimiento se traduce en la coexistencia de subjetividades, una individual que asume el proceso según su trayectoria singular y una subjetividad compartida que emerge del encuentro y de la historia común.

Parece apropiado sustentar que la experiencia formativa se constituye en un evento agenciante, y por el mismo, transformador de la subjetividad política de los jóvenes. Se entiende en este contexto que lo agenciante, tiene que ver con lo que apalanca, provoca o promueve el fortalecimiento de la capacidad política del sujeto (Martínez \& Cubides, 2012). Esto es posible en tanto va implicando a los sujetos jóvenes, al punto que les lleva a resignificar sus experiencias políticas, incidiendo en sus marcos de significación y acciones.

La manera en que se operan estas transformaciones no es exclusiva del espacio, sino que coincide con lo hallado en otros estudios sobre la formación política. Por ejemplo, la crítica constante de los jóvenes a la política tradicional es una acción contextuada que comprende y cuestiona las formas de poder y contrapoder localizados, además que se compartiese que no todo lo visto es la única posibilidad de vivir-se y que detrás de cada acción hay juegos de intereses o poderes que se pueden reorientar (Botero, Ospina, Gómez, \& Gutiérrez, 2008).

El encuentro se convierte en la incitación que invita a los procesos auto - eco - fomativos del sujeto. Este, siempre en relación a otros, opera reflexivamente sobre sus propios sentidos para generar posibilidades no-afirmativas o críticas, de convivencia con los otros, en el marco de unos intereses compartidos y de unos ideales que orientaran la permanente construcción y reconstrucción del orden social. Ya Alvarado y Carreño (2007), habían planteado que Ciudadanía, requiere de procesos educativos que preparen para la misma, haciendo que sujeto participe de toma de decisiones en beneficio del bien común y colectivo, acordes con principios y que la reflexividad: el sujeto se conoce a sí mismo en tanto también conoce al mundo y a los demás.

Las tensiones y las pugnas, consecuencias necesarias del encuentro de posturas diferentes, lógicas de interpretación y posicionamientos sobre sus realidades, se constituyen en plataformas para la orientación que va tomando el proceso formativo: tales tensiones, fueron dirimidas por vías legítimas, de suerte que la conflictividad de las relaciones políticas in situ, devinieron ejercicio democrático (Mouffe, 2007), condición por la cual se fueron superando exclusiones, imposiciones, repliegues y desmotivación.

Todo lo anterior, conduce a la idea de que el encuentro se va constituyendo en una fuente de experiencia política si se entiende que produce relaciones tensas entre diversidad de subjetividades políticas juveniles en devenir, y que esas tensiones se tramitan en ese espacio a través de mecanismos generadores de reconocimiento recíproco, a partir de los cuales se distingue lo común y lo diferente, y además se construye la significación de que las opciones políticas son múltiples.

El reconocimiento emana de la posibilidad de que una persona, grupo o colectividad se distinga políticamente de los demás, incluso para poder auto identificarse. Este reconocimiento/ diferenciación intersubjetiva define la especificidad de la persona, grupo, colectividad en un contexto social (Machín, 2004). Esa distintividad ha sido posible por medio de sentimientos y prácticas que identificaron a los participantes, y también por medio de sus narraciones. Narraciones que portaban los sentidos construidos en experiencias previas, en escenarios de 
interacción con otros pares coparticipes de procesos de formación anteriores. Narrar-se y narrar en general es una de las capacidades que median para ejercitar el reconocimiento del otro, poniéndose en su lugar. Aprender a hacerlo, significa aprender a narrar y a narrar-se de otra manera. Ponerse en el lugar del otro, demanda disposición hacia el otro en la vía de la mutualidad (Begué, 2005). En concordancia con Honneth (2006), el reconocimiento tratado como lo contrario de las prácticas de dominio o desprecio, admite que la acción está dirigida positivamente a la existencia de otra persona o grupo. El reconocimiento así visto, es una acción moral porque se deja orientar por el valor de las otras personas. Su ausencia, significa subordinación social, en tanto que imposibilidad de participar como igual en la vida social (Fraser, 2000). Tejer relaciones de convivencia fundamentadas en el reconocimiento del otro se constituye en fuente de las prácticas solidarias, justas, tolerantes y de civilidad (Ocampo, Méndez \& Pavajeau, 2008).

Lo que consideramos novedoso, es el carácter de encuentro, el aceptarlo como una situación formadora y potencialmente transformadora de subjetividades, y el que la memoria, la reflexividad, la tramitación de tensiones y la afectividad sean reconocidas para su existencia. Es importante la dimensión afectiva para llegar a la práctica del reconocimiento; en la situación de encuentro, la creación de cercanía y confianza entre los participantes ha sido imprescindible para tal fin, así como la capacidad de recobrar la calma y reflexionar sobre lo vivido; pero también se necesitó de la vehemencia, concomitante a la vivencia de las tensiones en la situación de aprendizaje. Hay que reconocer, que el cálculo racional de intereses y la deliberación moral, propias del liberalismo (Mouffe, 2007), son insuficientes para entender el campo político, que requiere de las "pasiones" como fuerza movilizadora.

Por su parte, la memoria y la reflexividad, como dos procesos que se imbricaron en el espacio formativo, fueron canales mediante los cuales los sujetos se encontraron en historias, unieron los hilos de su devenir como sujetos políticos, resignificaron sus dolores, pensaron sobre sus motivaciones y valoraron críticamente lo hasta el momento hecho.

¿Qué tiene que ver esto con las subjetividades políticas? El re-sentir, el re-flexionar y el resignificar, modifica sentidos subjetivos que se manifiestan claramente en testimonios que están hablando de lo que ha sido reconfigurado por ellos. Es decir, cada subjetividad particular experimenta reconfiguración. Pero también, en términos del reconocimiento de la diferencia implica una reconfiguración del espacio juvenil en términos de a quienes más consideramos, es decir, quienes más operan en lo pluriverso de lo juvenil; por eso se modifican los sentidos subjetivos de lo político, de la política, de lo diferente y lo diverso, pero también de los cursos de acción que pueden proseguir a partir de allí.

\section{Conclusiones.}

Es de resaltar el impacto positivo el que otros jóvenes sean los que pongan en común ante el grupo, sus experiencias de participación.

Dados los alcances de este estudio, no es nuestra pretensión hacer generalizaciones sobre lo que pueda resultar útil en todos los casos, sin embargo, al dar cuenta de las condiciones del proceso formativo que posibilitaron las transformaciones de las subjetividades políticas ya descritas, se pueden hacer aportes a otras experiencias que se propongan objetivos similares.

La denominada "apatía” política de los jóvenes es un tema de preocupación legítima para cualquier sociedad con una orientación democrática y por ello diversas instituciones ligadas al 
Estado, así como sectores de las organizaciones comunitarias, los movimientos sociales y la academia viene proponiendo reflexiones y estrategias en torno a la promoción de la participación política juvenil a través de proceso formativos.

La participación autónoma es prioritaria ya que, los jóvenes pueden ser protagonistas en la elección de los temas y metodologías, así como en su implementación, cuidando que no se genere una percepción de que los facilitadores son pasivos o que el proceso sea laxo.

Si las metodologías son diversas y creativas, sin perder su sentido pedagógico, promueven el trabajo colaborativo, y capturan el interés para los jóvenes, por ello resulta de vital importancia, la inclusión de técnicas artísticas, salidas de campo, la presentación de experiencias por parte de invitados, entre otras.

La co-presencia de la diversidad de posturas ideológicas, edades (en el rango de lo que se puede considerar "joven”) y experiencias de participación, lo cual hace que se produzcan tensiones que bien pueden dinamizar un proceso bien conducido, dejando que los actores sean capaces de autodirigirse.

Es clave no eliminar las tensiones, sino dejar que se desarrollen, a la vez que, en el espacio formativo se promueva el reconocimiento mutuo a través del acercamiento afectivo (confianza), la escucha y el respeto a los acuerdos (pactados).

Es por la emergencia de las tensiones y su trámite, a través del reconocimiento de la diferencia, que el espacio puede devenir él mismo, político.

Son los ejercicios de debate, los que propician intercambios comunicativos en los que se hace necesario argumentar y comprender los argumentos de los otros, asimismo, la propuesta de ejercicios que estimularan la reflexividad y memoria, como la redacción de relatos autobiográficos y su puesta en común.

La liberación de los afectos, como se desprende de lo estudiado por Roldán (2006) y la confianza, son un factor determinante en el propósito de posicionarse como sujeto político.

La confianza, también depende en buena parte de los dispositivos reales, ofrecidos por los(as) orientadores.as o creados por los y las jóvenes participantes, para establecer espacios de diálogo y deliberación desde condiciones de equidad y simetría como base de la participación.

Es así, que la confianza se construye y se va fortaleciendo en la medida en que los actores, identifiquen, nombren y reconozcan libre y mutuamente sus expectativas y compromisos.

Pero no ha de ignorarse que, por diversas circunstancias, los participantes pueden dejar conocer sus dolores, recuerdos, rabias, temores y demás, que pueden ser tramitados en relaciones de confianza con los otros.

\section{Bibliografía.}

Agudelo, A., \& Gaviria, M. (2014). Pedagogías Críticas y Producción de Subjetividades. En S. V. Alvarado, \& H. F. Ospina, Socialización Politica y Configuración de Subjetividades (págs. 265286). Bogotá: Siglo del Hombre Editores. 
Alcaldía de Medellín. (2009). Acción Colectiva, Juvenil en Medellín, "Una Realidad en continuo Movimiento". Medellín: Alcaldía de Medellín.

Alcaldía de Medellín. (2012). Índice de Desarrollo Juvenil. Medellín: Alcaldía de Medellín.

Alcaldía de Medellín. (2015). Plan Estratégico de Juventud de Medellín 2015-2027. Medellín: Alcaldía de Medellín.

Alvarado, S. V., \& Carreño, M. T. (2007). La Formación Ciudadana: Una Estrategia para la Construcción de Justicia. Revista Latinoamericana de ciencias sociales niñez y juventud, 5(1), 1 15.

Alvarado, S. V., Ospina Alvarado, M. C., \& García, C. M. (2012). La subjetividad política y la socialización política, desde las márgenes de la psicología política. Revista Latinoamericana de Ciencias Sociales, Niñez, y Juventud, 10(1), 235-256. Obtenido de http://revistaumanizales.cinde.org.co/index.php/RevistaLatinoamericana/article/view/597/326

Alvarado, S. V., Ospina, H. F., Botero, P., \& Muñoz, H. (2008). Las tramas de la subjetividad política y los desafíos a la formación ciudadana en jóvenes. Revista Argentina de Sociología(11), 19-43. Obtenido de http://www.scielo.org.ar/pdf/ras/v6n11/v6n11a03.pdf

Arendt, H. (1997). ¿Qué es política? Barcelona: Paidós.

Begué, M. F. (2005). De la tolerancia al reconocimiento mutuo. Strómata: Revista de Filosofía y Teología, 61(1/2), 153-164.

Benner, D. (1998). La pedagogía como ciencia. Barcelona: Ediciones Pomares - Corredor.

Bonvillani, A. (2012). Hacia la construcción de la categoría Subjetividad Política: Una posible caja de herramientas y algunas líneas de significación emergentes. En C. Piedrahita Echandía, Á. Díaz Gómez, \& P. Vommaro, Subjetividades políticas: Desafíos y debates latinoamericanos (págs. 191-202). Bogotá: Universidad Distrital Francisco José de Caldas.

Botero, P., Ospina, H. F., Gómez, E. A., \& Gutierrez Ospina, M. I. (2008). Condiciones de participación y formación política de jóvenes colombianos constructores de paz. Magis. Revista Internacional de Investigación en Educación(1), 81-94.

Cubides, H., Guerrero, P., Alaider, S., Hurtado, D., \& Restrepo, A. (2007). Jóvenes, Participación Política y Formación Democrática. Estudio comparado en Bogotá y Medellín. Nómadas(26), 230-233.

Díaz Gómez, A. (2012). Devenir subjetividad politica : un punto de referencia sobre el sujeto político. Manizalez: Centro de Estudios Avanzados en Niñez y Juventud, Universidad de Manizales y el CINDE. Obtenido de http://biblioteca.clacso.edu.ar/Colombia/alianzacinde-umz/20130401053108/TesisAlvaroDG.pdf 
Duque, L., Patiño, C., Muñoz, A., Villa, E., \& Cardona, J. (2016). La subjetividad política en el contexto latinoamericano. Una revisión y una propuesta. Revista CES Psicología, 9(2), $114-$ 127.

Fernández Christlieb, P. (2009). Lo psicosocial. El alma pública: Revista desdisciplinada de psicología social(4), 42-49. Recuperado el 2015 de Febrero de 23, de http://elalmapublica.net/pdf/AP4.pdf

Fraser, N. (2000). Nuevas reflexiones sobre el reconocimiento. New Left Review(4), 55-68. Obtenido de newleftreview.es/article/download_pdf?language $=$ es\&id $=2248$

Galeano, M. E. (2004). Diseño de proyectos en la investigación cualitativa. Medellín: Fondo Editorial Universidad EAFIT.

Garcés, A., \& Acosta, G. (2010). Ámbitos y Escenarios de Participación Política Juvenil en Medellín. Anagramas: Rumbos y Sentidos de la Comunicación, 8(16), 15-32.

González, F. (2008). Subjetividad social, sujeto y representaciones sociales. Revista Diversitas: perspectivas en psicología, 4(2), 225-243. Obtenido de http://www.usta.edu.co/otraspaginas/diversitas/doc_pdf/diversitas_8/vol.4no.2/arti culo_1.pdf

Henao, J., Ocampo, A., Robledo, A., \& Lozano, M. (2008). Los grupos juveniles universitarios y la formación ciudadana. Universitas Psychologica, 7(3), 853-867.

Honneth, A. (2006). El reconocimiento como ideología. Isegoría(35), 129-150. Obtenido de http://isegoria.revistas.csic.es/index.php/isegoria/article/viewArticle/33

Huerta, J. (2009). Formación ciudadana y actitudes hacia la participación política en escuelas primarias del noreste de México. Revista Mexicana de Investigación Educativa, 14(40), 121 145.

Hurtado, D. (2010). Los Jóvenes de Medellín: ¿Ciudadanos Apáticos? Nómadas(32), 99-115.

Lozano, M. (2008). Los procesos de subjetividad y participación política de estudiantes de psicología de Bogotá. Revista Diversitas: Perspectivas en psicología, 4(2), 345-357. Obtenido de http:/ / www.scielo.org.co/scielo.php?pid=S1794-

99982008000200011\&script=sci_arttext

Lüth, C. (2001). De las teorías de la Bildung en Alemania: aspectos de su desarrollo desde 1960. En Encuentros Pedagógicos Transculturales. Medellín: Universidad de Antioquia.

Machín, J. (2004). Identidades juveniles. Prolegómeno de un modelo heurístico. JOVENes, Revista de Estudios sobre Juventud, 8(21), 54-75.

Magendzo, K. (2007). Formación de Estudiantes Deliberantes para una Democracia Deliberativa. REICE, Revista Electrónica Iberoamericana sobre Calidad, Eficacia y Cambio en Educación, 5(4), 70-82. 
Martínez, M., \& Cubides, J. (2012). Acercamientos al uso de la categoría de "Subjetividad política" en procesos investigativos. En C. Piedrahita, A. Díaz, \& P. Vommaro, Subjetividades políticas: Desafíosy debates latinoamericanos (págs. 169-190). Bogotá: Universidad Distrital Francisco José de Caldas. Obtenido de http://biblioteca.clacso.edu.ar/clacso/coediciones/20130218032232/Subjetividadespo liticas.pdf

Molina, N. (2013). Discusiones acerca de la Resignificación y Conceptos Asociados. Revista MEC-EDUPAZ(3), 39-63.

Mouffe, C. H. (2007). En torno a lo político. Buenos Aires: Fondo de cultura económica.

Ocampo Talero, A. M., Méndez París, C., \& Pavajeau Delgado, S. (2008). Las subjetividades como centro de la formación ciudadana. Universitas Psychologica, 7(3), 837-851.

Restrepo, A. (2010). Los Jóvenes y sus Luchas por el Reconocimiento. Nómadas(32), 179-193.

Roldán, O. (2006). La institución educativa: escenario de formación política, que se configura desde el ejercicio mismo de la política. Manizales: Centro de Estudios Avanzados en Niñez y Juventud, Universidad de Manizalez y el CINDE.

Runge, A. (2005). Foucault : la revaloración del maestro como condición de la relación pedagógica y como modelo de formación : una mirada pedagógica a la hermeneútica del sujeto. En O. L. Zuluaga Garcés, C. E. Noguera Ramírez, \& H. Quiceno Castrillón, Foucault, la pedagogía y la educación : pensar de otro modo (págs. 201-228). Bogotá: Magisterio.

Runge, A., \& Muñoz, D. (2005). Mundo de la vida, espacios pedagógicos, espacios escolares y excentricidad humana: reflexiones antropológico-pedagógicas y socio-fenomenológicas. Revista Latinoamericana de Ciencias Sociales, Niñezy Juventud, 3(2), 51-81.

Sujetos y subjetividades políticas: El caso del movimiento juvenil Álvaro Ulcué. (2012a). Revista Latinoamericana de Ciencias Sociales, Niñez y Juventud, 10(2), 855-869. Obtenido de http://revistaumanizales.cinde.org.co/index.php/RevistaLatinoamericana/article/view/743/387

Tajfel, H. (1984). Grupos Humanos y categorías sociales. Barcelona: Herder.

Tassin, E. (2012). De la subjetivación política. Althusser/Ranciére/Foucault/Arendt/Deleuze. Revista de Estudios Sociales(43), 36-49. Obtenido de http:/ / res.uniandes.edu.co/view.php/780/index.php?id=780

Torres, A. (2009). Acción colectiva y subjetividad. Un balance desde los estudios sociales. Folios. Segunda éroca(30), 51-74. Obtenido de http:/ /www.scielo.org.co/scielo.php?script=sci_arttext\&pid=S0123$48702009000200004 \& \operatorname{lng}=\mathrm{es} \& \mathrm{nrm}=. \mathrm{pf} \& \ln \mathrm{ln}=\mathrm{es}$

Vierhaus, R. (2002). Formación (Bildung). Medellín: Universidad de Antioquia. 


\section{Nota.}

${ }^{i}$ Este trabajo se ha generado en el marco del proyecto de Investigación: "Formación de sujetos y construcción de subjetividades críticas en la configuración de tejido social en la ciudad de Medellín y en el área metropolitana, con jóvenes, educadores y líderes comunitarios"; financiada por la USB Medellín y con apoyo del IPECAL - México y llevada a cabo entre agosto del 2014 y diciembre del 2015. 